\title{
Dynamic Analysis on Particle Concentration Induced by Opening the Door of a Front Opening Unified Pod (FOUP) that Loaded with 25 Pieces of 300 mm Wafer Manufacturing Processes
}

\author{
Shih-Cheng $\mathrm{Hu}^{1 *}$, Chen-Wei Ku${ }^{1}$, Yang-Cheng Shih ${ }^{1}$, Kwen Hsu ${ }^{2}$ \\ ${ }^{1}$ Department of Energy and Refrigerating Air-Conditioning Engineering, \\ National Taipei University of Technology, Taipei Taiwan \\ ${ }^{2}$ TRW Company, Detroit Michigan, USA
}

\begin{abstract}
This study investigates experimentally and numerically the influences of FOUP door opening speed $\left(\mathrm{V}_{\mathrm{door}}\right)$ and the pressure difference $(\mathrm{dP})$ on the dynamic distributions of the averaged nondimensional particle concentration in the FOUP $\left(\mathrm{C}_{\mathrm{ave}}\right)$, which is defined as averaged particle concentration in the FOUP $\left(\mathrm{c}_{\mathrm{ave}}\right)$ divided by the particle concentration in the clean room $\left(\mathrm{c}_{\mathrm{CR}}\right)$. Here $\mathrm{dP}$ is the difference between the mini-environment pressure and the clean-room pressure. Results show that when $\mathrm{V}_{\text {door }}$ lies between $0.05 \mathrm{~m} / \mathrm{s} \sim 0.15 \mathrm{~m} / \mathrm{s}$ and $\mathrm{dP}$ within $0.3 \mathrm{~Pa}-12.7 \mathrm{~Pa}, \mathrm{C}_{\text {ave }}$ proportional to $1 / 2 \rho \mathrm{V}_{\mathrm{door}}{ }^{2}$ and inversely proportional to $\mathrm{dP}$. This can be expressed by a stepwise multiple regression equation: $\mathrm{C}_{\mathrm{ave}}=4.56 \times 10^{-1}\left(1 / 2 \rho \mathrm{V}_{\mathrm{door}}^{2}\right)-4.6 \times 10^{-4} \mathrm{dP}+4.96 \times 10^{-3}$.
\end{abstract}

Keywords: FOUP; Minienvironment; Clean room; Semiconductor processes.

\section{INTRODUCTION}

In line with improvement in production techniques, the rise in the number of $300 \mathrm{~mm}$ wafer manufacturing factories is a natural trend. As opposed to factories producing the smaller $200 \mathrm{~mm}$ wafer, these factories use wafer loading/unloading modules with FOUP/LPU combined with mini-environment.

\footnotetext{
*Corresponding author. Tel.: 886-2-2771-2171 ext.

3512; Fax: 886-2-2731-4919

E-mail address: f10870@ntut.edu.tw
}

The entire module is composed of three main components, namely, a mini-environment, a LPU and a FOUP, as illustrated in Fig. 1. Their main functions are detailed as follow.

\section{Mini-environment \\ Mini-environment is a small-scale clean environmental mechanism housing the entire wafer production facilities to ensure that the processing of wafer is carried out in a controllable high level of cleanliness. Each production tool has its individual mini- environment whose clean air is provided by a}




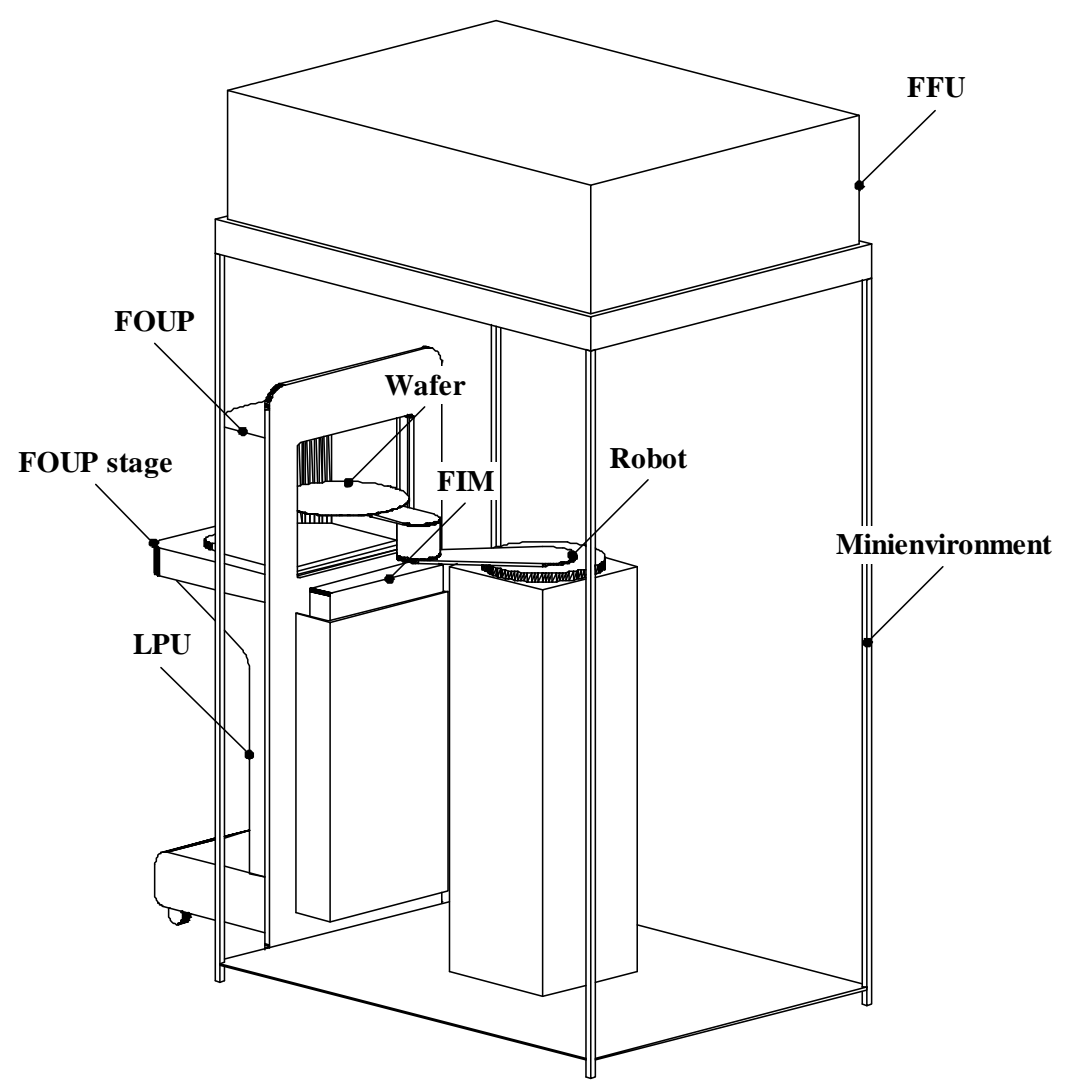

Fig. 1. Components of a FOUP/LPU loading/unloading module

Fan Filter Unit (FFU) that maintains a positive pressure to form a unique isolated environment, shielded from external contamination including particle $(\mathrm{Hu}$ and Hsiao, 2003) and airborne molecular contaminant (Chien et al., 2007; Li et al., 2007). According to the technical manual published by SEMATECH (1996), the design criteria stipulate that the air velocity in a minienvironment for producing $300 \mathrm{~mm}$ wafer must be between $0.2 \mathrm{~m} / \mathrm{s}$ and $0.45 \mathrm{~m} / \mathrm{s}$ while the pressure difference (between the minienvironment and the clean room) must be maintained at above $1.27 \mathrm{~Pa}$ but below $100 \mathrm{~Pa}$. As the mini-environment is created by the isolation technique, the air space to be controlled is largely reduced and therefore relatively easy to achieve higher level of cleanliness compared with the several technical problems faced in maintaining cleanliness in a large ballroom environment.

\section{Load Port Unit (LPU)}

The main function of the LPU is to open/close the door of the FOUP such that the wafer stored in the FOUP can be loaded into the manufacturing machine. Its main components are a FOUP Stage and a Frontopening Interface Mechanism (FIM).

\section{FOUP}

This is the container storing the wafer and is air-tight sealed to shelter the wafer from any contact with the environment in the conveying process to prevent particle contamination. A FOUP can store up to 25 pieces of wafer. The 
operating procedure of the FOUP/LPU loading module can be illustrated by five main processes as shown in Fig. 2.

Through an Automated Material Handling Module (AMHS) or an operator, a FOUP wafer-containing is first positioned on the stage with a kinematic coupling pin. In the second process, the stage will convey the FOUP forward until the latch on the FOUP door and the latch key on the front-opening interface mechanism are securely fastened. The third process, the latch key then rotates to open the door of the FOUP and moves backwards towards its initial position, completing the full opening operation of the FOUP door. In fourth process, the entire frontopening interface mechanism moves downwards into the LPU. In the final process, each wafer is then moved into the minienvironment to be loaded in sequence into the processing tool chamber by a robotic arm for processing. This study focuses on process 3 , in which the wafer is most likely to be contaminated. The ISO and IEST publish the methods or protocols on construction and operation of minienvironments and clean rooms (Tannous et al., 1997; ISO 14644-1, 1999; Hu et al., 2002). For the 8 inch wafermanufacturing, some studies or benchmarking activities addressed the impact of production yields by adopting minienvironments (IEST, 1995; Rothman et al., 1995). Xu (2007) indicates that at a steady state, pressure differentials as low as under 0.2 Pa can be sufficient for achieving a high level of air cleanliness to meet environmental control expectation and requirements.
Previous studies in this subject of minienvironment for loading/unloading 12 inch wafer are rare. Kobayashi et al. (2000) performed particle per wafer per pass (PWP) testing on particles with diameters greater than or equal to $0.12 \mu \mathrm{m}$, for wafers in the FOUP when the FOUP door opening. Neglecting the pressure difference, they reported that the PWP value of the top wafer (wafer 25) is the highest. Moreover, the door-opening speed affects most strongly the PWP value. However, the PWP test cannot identify the effect of individual source of particle. The author's previous studies (Hu et al., 2003; 2005) identified the influence of various particle sources on wafer when the wafer is at various positions in the minienvironment. Further investigation is needed for the following reasons. Firstly, to our knowledge, no literature has provided information of particle migration at the instance of door opening of a FOUP for 12 inch wafer manufacturing. Secondly, previous studies have used singlepoint monitoring technique for particle measurement. The multi-point laser particle counter provides more meaningful data than the common single-point monitoring. The data obtained at different locations show that this monitoring approach can detect significant number of particles in a FOUP that has been reported to be mainly particle-free. This study therefore aims to use both experimental and CFD approaches to elucidate particle transport and pressure difference characteristics in a FOUP/LPU minienvironment system at the instant when the FOUP door opens. 




Fig. 2. The operating procedure (processes $1 \sim 5$ (from left to right)) of unloading of a wafer.

\section{STUDY METHODS}

\section{Experimental Approach}

The experiment was carried out in a cleanroom. By adjusting the frequency of the inverter of supply air fan, various cleanliness levels ranging from ISO Class 1 to ISO Class 6 were achieved. The temperature and relative humidity were maintained at $22 \pm 1^{\circ} \mathrm{C}$ and 55 $\pm 5 \%$ R.H., respectively. The multi-point laser particle counter (Mini-Net 310 PMS) was used to monitor particle concentration in the FOUP. The multi-point laser particle counter used an "ensemble manifold" to draw particle samples simultaneously from seven sampling points, at a combined rate of $1 \mathrm{ft}^{3} / \mathrm{min}$. A particle counter then samples this mixed air. As a result, the particle counts represent the total number of particles from all sites, rather than from one site at a time. The results provide more meaningful data than the common single-point monitoring.

\section{CFD Approach}

The CFD study was performed by using a commercial code-FLUENT (version 6.2), which has been extensively validated in solving various types of turbulent flows. The physical model for CFD study is shown in Fig. 3. The following assumptions were made:

1. The fluid is air and the flow field is twodimensional, incompressible and turbulent.

2. The fluid properties are constant and the effect of gravity is neglected.

3. The no-slip condition is held on all interfaces.

The dynamic mesh model in FLUENT can be used to model flows where the shape of the domain is changing with time due to motions of the domain boundaries. In the case the motion is a prescribed motion, in other words the subsequent motions of the boundaries are independent of the simulated flow at the current time. The update of the volume mesh is handled automatically by FLUENT at each time step based on the new positions of the boundaries. The integral form of the conservation equation for a general scalar $\Phi$ on an arbitrary control volume, V, whose boundary is moving can be written as: 


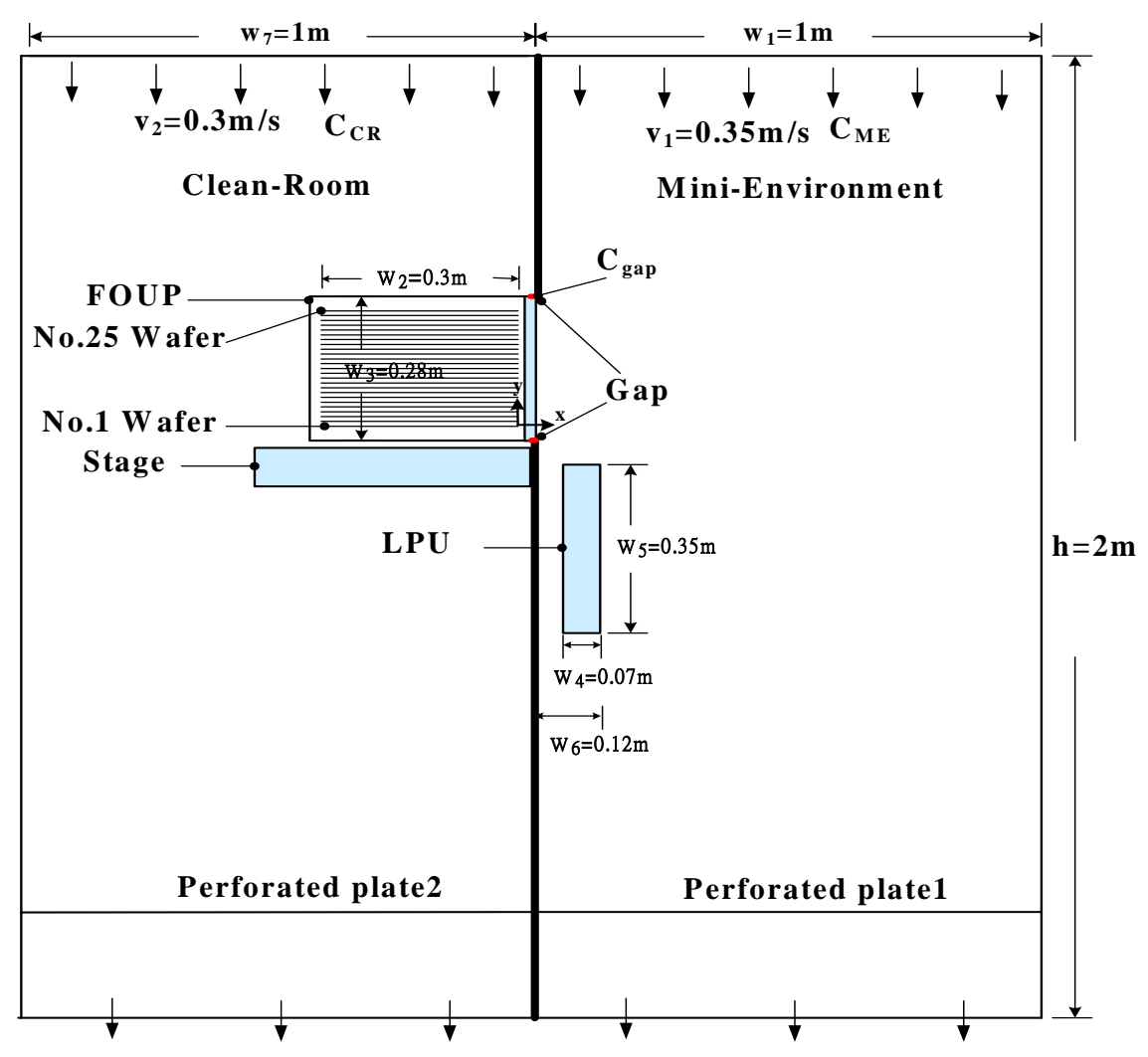

Fig. 3. The physical model for CFD study.

$$
\begin{aligned}
& \frac{d}{d t} \int_{V} \rho \phi d V+\int_{\partial V} \rho \phi\left(\vec{u}-\vec{u}_{g}\right) \cdot d \vec{A}-\int_{\partial V} \Gamma \nabla \phi \cdot d \vec{A} \\
& =\int_{V} S_{\phi} d V
\end{aligned}
$$

Where $\phi$ represents each of the velocity components $\mathrm{v}$ and $\mathrm{u}$, the turbulence kinetic energy $(\mathrm{k})$, the dissipation rate of the turbulence kinetic energy $(\varepsilon)$, and the particle concentration (c). $\rho$ is the fluid density, while $\vec{u}$ is the flow velocity vector, $\vec{u}_{g}$ is the grid velocity of the moving mesh, $\Gamma$ is the diffusion coefficient for the dependent variable $\phi, S_{\phi}$ is the source term of $\phi$ and $\partial V$ is the boundary of the control volume V. Using a first-order backward difference formula, the time derivative term in Eq. (1) can be written as follows: $\frac{d}{d t} \int_{V} \rho \phi d V=\lim _{\Delta t \rightarrow 0} \frac{(\rho \phi V)^{n+1}-(\rho \phi V)^{n}}{\Delta \mathrm{t}}$

where $\mathrm{n}$ and $\mathrm{n}+1$ denote the respective quantities at the current and next time levels. The $(\mathrm{n}+1)$ time level volume $\mathrm{V}^{\mathrm{n}+1}$ is computed from

$V^{n+1}=V^{n}+\frac{d V}{d t} \Delta t$

where $\mathrm{dV} / \mathrm{dt}$ is the volume time derivative of the control volume. In order to satisfy the grid conservation law, the volume time derivative of the control volume is computed from

$$
\vec{u}_{g, j} \cdot \vec{A}_{j}=\frac{\delta V_{j}}{\Delta t}
$$


where $\delta V_{j}$ is the volume swept out by the control volume face $\mathrm{j}$ over the time step $\Delta \mathrm{t}$.

The SIMPLE solver (Patankar, 1980), modified for use in particle transport problem by Stratmann and Whitby (1989) is used to solve the differential equations. The velocity fields are calculated first using the NavierStokes equation; these discrete values are then used as input into the diffusion equation. The boundary conditions are as shown in Fig. 3, where the gap between minienvironment and FOUP is $0.002 \mathrm{~m}$. During the open period, the door was horizontally moved for $0.1 \mathrm{~m}$. For the supply inlets (on the ceiling), the following boundary conditions are applied. The supply inlet flow of the minienvironment is defined as entering the minienvironment with a constant, uniform velocity and a constant, uniform particle concentration, that are $\mathrm{v}_{1}=$ $0.35 \mathrm{~m} / \mathrm{s}$, and $\mathrm{c}_{1}=0.0$ particle $/ \mathrm{m}^{3}$, respectively. In addition, $\mathrm{k}_{1}=0.002 \mathrm{v}_{1}^{2}$ and $\varepsilon_{1}=C_{\mu}^{3 / 4} \frac{k_{1}^{1.5}}{l_{1}}$ with the mixing length $1_{1}=0.07 \mathrm{~L}_{1}$, where $\mathrm{L}_{1}$ is the hydraulic diameter of the supply inlet of the minienvironment. The clean room environment was assumed to be under supply air conditions: $\mathrm{v}_{2}=0.35 \mathrm{~m} / \mathrm{s}, \mathrm{c}_{2}=1,000$ particles $/ \mathrm{m}^{3}, \mathrm{k}_{2}=0.002 \mathrm{v}_{2}^{2}$ and $\varepsilon_{2}=C_{\mu}^{3 / 4} \frac{k_{2}^{1.5}}{l_{2}}$, $l_{2}=0.07 \mathrm{~L}_{2}$, where $\mathrm{L}_{2}$ is the hydraulic diameter of the supply inlet of the clean room. Neumann boundary conditions were applied at the outlet to satisfy the mass conservation law. The standard wall function was employed to interpret the turbulent flow properties in near wall regions. The perforated plate in the clean room and the minienvironment was modeled as a finite thickness over which the pressure drop $(\mathrm{dP})$ is defined as a combination of Darcy's Law and an additional inertial loss term:

$$
d P=-\left(\frac{\mu}{\alpha} V_{n}+C_{p j} \frac{1}{2} \rho V_{n}^{2}\right) \Delta m
$$

where $\mu$ is the laminar fluid viscosity $\left(\frac{N-s}{m^{2}}\right)$, $\alpha$ is the permeability of the perforated plate $\left(\mathrm{m}^{2}\right), \mathrm{C}_{\mathrm{pj}}$ is the pressure-jump coefficient, $\mathrm{V}_{\mathrm{n}}$ is the velocity normal to the porous face $(\mathrm{m} / \mathrm{s})$, and $\Delta \mathrm{m}$ is the thickness of the perforated plate (m). The relationship between pressure jump over the perforated plate and the open ratio of the perforated plate $(\beta)$ was modeled by:

$$
d P=\left(\frac{1-\beta}{\beta^{2}}\right)(\rho) V_{n}^{2}
$$

Using Eqs. (5) and (6), we can determine the values of $\alpha$ and $C_{p j}$. We investigated the door-opening speed from $0.05 \mathrm{~m} / \mathrm{s}, 0.1 \mathrm{~m} / \mathrm{s}$ to $1.5 \mathrm{~m} / \mathrm{s}$, and pressure differences from $0.3 \mathrm{pa}$, $6 \mathrm{pa}, 9$ pa to $12.7 \mathrm{~Pa}$. The following nondimensional particle concentrations were used in the section of results and discussion. These are:

$$
C_{\text {wafer }}=\frac{C_{\text {wafer }}}{C_{C R}}, C_{\text {gap }}=\frac{C_{\text {gap }}}{C_{C R}} \text { and } C_{\text {ave }}=\frac{C_{\text {ave }}}{C_{C R}}(7)
$$

where $c_{C R}\left(\right.$ particles $\left./ \mathrm{m}^{3}\right)$ is the particle concentration in cleanroom, $\mathrm{c}_{\text {wafer }}$ (particles $/ \mathrm{m}^{3}$ ) 
is the particle concentration on the first grid next to the wafer surface, $c_{\text {gap }}$ (particles $/ \mathrm{m}^{3}$ ) is the particle concentration at the gap, $c_{a v e}$ (particles $/ \mathrm{m}^{3}$ ) is the averaged particle concentration in the FOUP.

\section{RESULTS AND DISCUSSION}

Fig. 4 shows the comparison of predicted and measured $\mathrm{C}_{\mathrm{ave}}$ vs. $\mathrm{dP}$ for high door opening velocity cases $\left(\mathrm{V}_{\text {door }}=0.15 \mathrm{~m} / \mathrm{s}\right)$. The Fig. 4 shows that a difference of $15 \%$ for low pressure case i.e $0.3 \mathrm{~Pa}$ and good agreement for higher pressure cases.

Typical surface particle concentration values for the cases studied are shown in Fig. 5. A high $\mathrm{V}_{\text {door }}$ case corresponding to a high peak value of $\mathrm{C}_{\mathrm{wafer}}$. The peak value of $\mathrm{C}_{\mathrm{wafer}}$ appears between the $20^{\text {th }}$ and $25^{\text {th }}$ wafers. The peak value of $\mathrm{C}_{\mathrm{wafer}}$ for high $\mathrm{V}_{\text {door }}$ case $\left(\mathrm{V}_{\text {door }}=\right.$ $0.15 \mathrm{~m} / \mathrm{s}$ ) is about 3 times high than for low $\mathrm{V}_{\text {door }}$ case $\left(\mathrm{V}_{\text {door }}=0.05 \mathrm{~m} / \mathrm{s}\right)$. In general, a prepositional linear relationship between the door moving velocities to the peak particle concentration at the wafer surface $\left(\mathrm{C}_{\text {wafer }}\right)$ is noticed.

Fig. 6 shows the instantaneously induced particle concentration value at the gap position $\left(\mathrm{C}_{\text {gap }}\right)$ vs. the FOUP door-opening speed when $\mathrm{dP}$ is $9 \mathrm{~Pa}$. Note that the induced peak particle concentration ratio $\mathrm{C}_{\text {gap }}$ indicates instantaneous risk of particle ingression. When FOUP $\mathrm{V}_{\text {door }}$ is $0.05,0.1$ and $0.15 \mathrm{~m} / \mathrm{s}$, the peak particle concentration ratios $\mathrm{C}_{\text {gap }}$ were 0.124 , 0.228 and 0.398 , respectively. Same as the $\mathrm{C}_{\text {wafe, a }}$ a prepositional linear relationship between the moving velocities to the peak particle concentration at the gap $\left(\mathrm{C}_{\mathrm{gap}}\right)$ is observed.

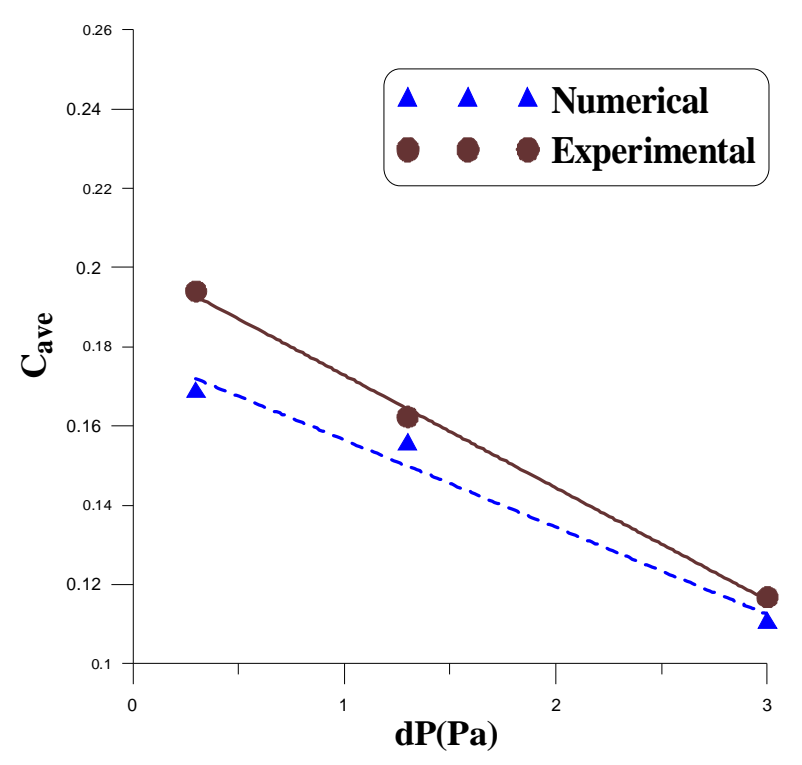

Fig. 4. Comparison of predicted and measured non-dimensional particle concentration $\mathrm{C}_{\mathrm{ave}} \mathrm{vs}$. $\mathrm{dP}$ for high door opening velocity cases $\left(\mathrm{V}_{\text {door }}\right.$ $=0.15 \mathrm{~m} / \mathrm{s}$ ).



Fig. 5. non-dimensional particle concentration $\mathrm{C}_{\text {wafer }}$ vs. number of wafer at $\mathrm{V}_{\text {door }}=0.15 \mathrm{~m} / \mathrm{s}$ and $\mathrm{dP}=0.3 \mathrm{~Pa}$. 


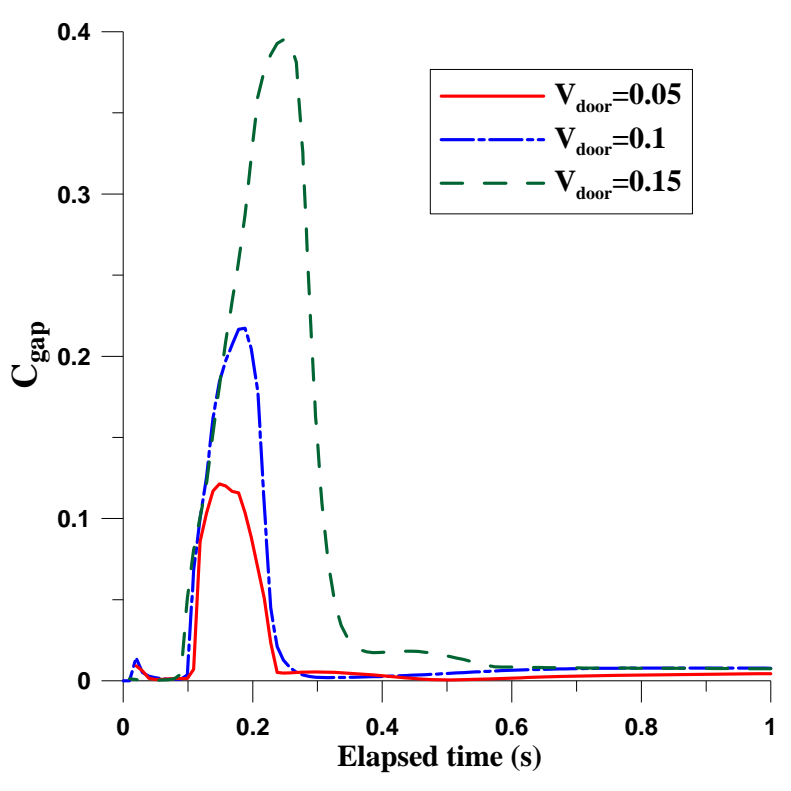

Fig. 6. Time history of non-dimensional particle concentration at the gap during dooropening period for different door-opening speeds when $\mathrm{dP}$ is $9 \mathrm{~Pa}$.

Fig. 7 shows the simulated particle concentration values for $\mathrm{V}_{\text {door }}$ ranging from $0.05 \mathrm{~m} / \mathrm{s}$ to $0.15 \mathrm{~m} / \mathrm{s}$ and $\mathrm{dP}$ ranging from 0.3 pa to $12.7 \mathrm{~Pa}$. By applying the Stepwise Multiple Regression method, the following regression equations are obtained from the simulated data. It shows the influences of door opening velocity energy $1 / 2 \rho \mathrm{V}_{\text {door }}^{2}$ and system pressure $\mathrm{dP}$ on the non-dimensional particle concentration $\mathrm{C}_{\mathrm{ave}}$, where the determinant $\mathrm{R}^{2}=$ 0.895 and corrected value is $\mathrm{R}^{2}=0.872$.

$$
\begin{aligned}
& \mathrm{C}_{\text {ave }}=4.56 \times 10^{-1}\left(1 / 2 \rho V_{\text {door }}{ }^{2}\right)-4.6 \times 10^{-4} d P \\
& +4.96 \times 10^{-3}
\end{aligned}
$$

When only the dynamic energy term is taken into account, the $\mathrm{R}^{2}$ value is equal to 0.482 . However, as the pressure term is added, the $\mathrm{R}^{2}$ value is significantly increased to 0.895 .
This means that the regression line fitting increases by $41.3 \%$. Generally, the terms of $1 / 2 \rho \mathrm{V}_{\text {door }}{ }^{2}$ and $\mathrm{dP}$ contribute to $87.2 \%$ of the estimated $\mathrm{C}_{\mathrm{ave}}$ value. The $1 / 2 \rho \mathrm{V}^{2}$ door term increases the $C_{a v e}$ value, but the $d P$ factor reduces the $\mathrm{C}_{\mathrm{ave}}$ value.

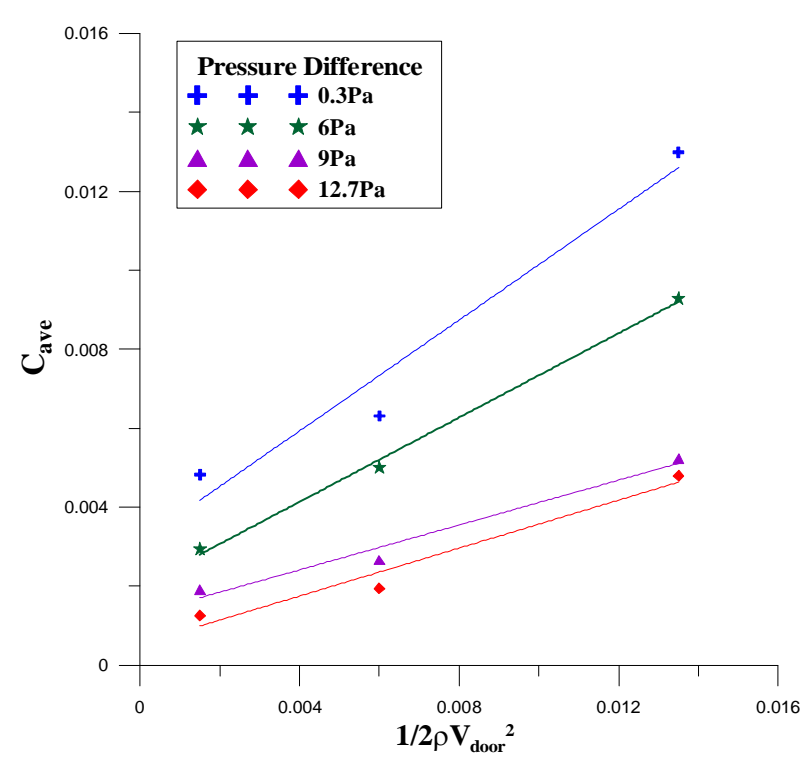

Fig. 7. Simulated non-dimensional particle concentration values for the cases studied.

\section{CONCLUSIONS}

FOUP door opening speed $\left(\mathrm{V}_{\text {door }}\right)$ and the pressure difference (dP) on the dynamic distributions of the averaged non-dimensional particle concentration in the FOUP $\left(\mathrm{C}_{\mathrm{ave}}\right)$, on the wafer surfaces $\left(\mathrm{C}_{\text {wafer }}\right)$, and at the gap between FOUP and the minienvironment, are studied. When $\mathrm{V}_{\text {door }}$ lies between 0.05 $\mathrm{m} / \mathrm{s} \sim 0.15 \mathrm{~m} / \mathrm{s}$ and $\mathrm{dP}$ within $0.3 \mathrm{~Pa}-12.7 \mathrm{~Pa}$, $\mathrm{C}_{\text {wafer, }} \mathrm{C}_{\text {gap }}$ and $\mathrm{C}_{\mathrm{ave}}$ linearly proportional to $\mathrm{V}_{\text {door }}$ and inversely proportional to $\mathrm{dP}$. The peak value of $\mathrm{C}_{\text {wafer }}$ appears between the $20^{\text {th }}$ $25^{\text {th }}$ wafers. The relationship between $C_{a v e}$, 
$\mathrm{V}_{\mathrm{door}}$ and $\mathrm{dP}$ can be expressed by a stepwise multiple regression equation as:

$$
\begin{aligned}
& \mathrm{C}_{\text {ave }}=4.56 \times 10^{-1}\left(1 / 2 \rho V_{\text {door }}^{2}\right)-4.6 \times 10^{-4} d P \\
& +4.96 \times 10^{-3}
\end{aligned}
$$

\section{ACKNOWLEDGMENT}

The authors would like to thank the National Science Council of Taiwan for financially supporting this research under Contract No. NSC 95-2622-E-027-047-CC3.

\section{REFERENCES}

Chien, C.L., Tsai, C.J., Ku, K.W. and Li, S.N. (2007). Ventilation Control of Air Pollutant during Preventive Maintenance of a Metal Etcher in Semiconductor Industry. Aerosol Air Qual. Res. 7: 469-488.

Fluent 6 User's Guide Vol. 2 and 3 (1998). Fluent Inc. Lebanon, NH 03766 USA.

$\mathrm{Hu}$ S.C. and Hsiao, T.R. (2005). Particle Dynamics in a Front-opening Unified $\mathrm{Pod} /$ load Port Unit Minienvironment in the Presence of a $300 \mathrm{~mm}$ Wafer in Various Positions. Aerosol Sci. Technol. 39: 185-95. $\mathrm{Hu}$, S.C. and Wu, T.M. (2003). Experimental Studies of Airflow and Particle Characteristics of a $300 \mathrm{~mm}$ POUP/LPU Minienvironment System. IEEE Trans. 16: 660-667.

Hu, S.C., Chuah, Y.K. and Yen, M.C. (2002). Design and Evaluation of a Minienvironment for Semiconductor Manufacture processes. Build Environ. 37: 201-208.
"I300I $300 \mathrm{~mm}$ Equipment Performance Metrics". International SEMATECH. (1996). Austin, TX.

International Organization for Standardization (ISO). ISO 14644-1, Cleanrooms and Associate Controlled Environments-Part 1classification of Air Cleanliness. The Institute of Environmental Sciences and Technology (IEST). 5005 Newport Drive, Suite 506, Rolling Meadows, IL 60008, USA, 1999. p. 18.

International Organization for Standardization (ISO). ISO 14644-3, Cleanrooms and Associate Controlled Environments-Part 3: Metrology and Test Methods. The Institute of Environmental Sciences and Technology (IEST). 5005 Newport Drive, Suite 506, Rolling Meadows, IL 60008-3841, USA, 2002. p. 65.

International Organization for Standardization (ISO). ISO 14644-4, Cleanrooms and Associate Controlled Environments-Part 4: Design, Construction and Start-up. The Institute of Environmental Sciences and Technology (IEST). 5005 Newport Drive, Suite 506, Rolling Meadows, IL 600083841, USA, 2001. p. 54.

International SEMATECH. Integrated minienvironment Design Best Practices, Technology Transfer \# 99033693A-ENG. Austin, TX, USA: International SEMATECH, Inc.; 1999.

Kobayashi, Y., Kobayashi, S., Tokunaga, K., Kato, K. and Minami, T. (2000). Particle Characteristics of 300-mm Minienvironment (FOUP and LPU). IEEE Trans. 13: 259-263. 
Li, S.N., Shih, H.Y., Yen, S.Y. and Yang, J. (2007). Case Study of Micro-Contamination Control. Aerosol Air Qual. Res. 7: 432-442.

Rothman, L., Miller, R., Wang, R., Baechle, T., Silverman, S. and Cooper, D. (1995). SEMATECH Minienvironment Benchmarking Project. J. of the IEST. 38: 36-41.

Shu, S. (1995). The Impact of Minienvironment of Fab Capacity and Yield. In: Proc. $41^{\text {st }}$ Annual Technology Meeting. Anaheim, CA: The Institute of Environmental Sciences and Technology. (IEST). p. 118-123.
Tannous, G. (1997). Optimization of a Minienvironment Design Using Computational Fluid Dynamics. J. of the IEST. 40: 29-34.

Tengfang Xu. (2007). Characterization of Minienvironments in a Clean Room: Design Characteristics and Environmental Performance. Build Environ. 42: 2993-3000.

Received for review, November 18, 2008 Accepted, December 27, 2008 